\title{
Surgery During COVID-19 Era An Overview
}

Abstract

COVID-19 pandemic has affected more than 215 countries worldwide. Patient management has seen a tremendous change in the current pandemic with many specialities adopting measures to contain human to human transmission of the virus and to make judicious use of resources available. Surgical practices have changed globally with use of virtual consultation, prioritisation of all elective and non-emergency services, COVID swab testing, chest imaging for all patients undergoing surgery and use of PPE to ensure staff safety. A major impact of COVID-19 has been on emergency surgery services and on the surgical training. This article highlights the impact of COVID-19 on safe delivery of surgical services and emphasizes on use of webinars, online teaching and simulation as a meaningful tool to deliver surgical training in COVID era.

Keywords; COVID-19, surgery, impact, PPE, training.

\section{Anil Kumar1, Meghana Taggarsi2 \& CR Selvasekar3}

1 International Training Fellow, General \& Colorectal

Surgery, Stepping Hill Hospital, Stockport, UK

2. Senior Clinical Fellow, General \& Hepatobiliary

Surgery, Royal Blackburn Hospital, Blackburn, UK

3. Consultant General, Colorectal, Laparoscopic \& Robotic Surgeon, Director of Surgery, Wade Professor of Surgical Studies, RCS Ed; The Christie Hospital, Manchester UK

Nettyanil@gmail.com

Article Information

Submitted 17 June 2020

Pre-print 18 June 2020

\section{Full Text}

\section{Introduction:}

COVID-19 pandemic has affected more than 215 countries globally. It was declared a Global Public Health Emergency by World Health Organisation (WHO) on January 30th 20201. According to the official World Health Organisation site, as of 29th May 2020, there are 5,704,736 infected cases worldwide, resulting in 357,736 deaths. United Kingdom is amongst the top 5 worst affected countries at the time of writing this review 2. To combat the effects of corona pandemic, meticulous use of available resources is crucial. In order to minimize resource exhaustion, the use of surgical appliances and staff must be well contemplated and balanced 3. Surgical practices have changed in U.K. and worldwide, which includes prioritisation of all elective and non-emergency surgeries, use of virtual consultation wherever possible, reduction in face to face consultations, suspension of endoscopy services, etc. However, acute surgical emergencies are inevitable and should be managed in a timely manner in order to avoid patient morbidity and mortality.

COVID-19 is a newly emerged zoonotic coronavirus which causes an acute respiratory disease. It is a single stranded enveloped RNA virus, which was isolated from a patient suffering with pneumonia in Wuhan where it originally began. Genetic analysis revealed that COVID-19 is closely related to Severe Acute Respiratory Syndrome Coronavirus (SARS-CoV) and has been named as SARS-CoV-2, it belongs to the genus Beta coronavirus, subgenus Sarbecovirus. The transmission of the virus occurs from human to human via droplets and by touching the droplet-contaminated surfaces or objects 4 . COVID-19 pandemic has had an immense impact on the management of surgical emergencies. In order to limit the exposure of healthcare personnel to COVID and suspected COVID patients, the four Royal College of Surgeons (RCS), 
Association of Coloproctology of Great Britain and Ireland (ACPGBI), Association of Surgeons of Great Britain and Ireland(ASGBI) and Association of Upper Gastrointestinal Surgery of Great Britain and Ireland (AUGIS) proposed guidelines in March 2020, for triage of patients with acute surgical emergencies 5,6.

Before the COVID-19 pandemic, the standard of treatment for acute appendicitis and acute cholecystitis was surgery either through laparoscopy or open method 7,8 but since the outbreak of COVID-19, it has been suggested that for uncomplicated acute appendicitis, acute cholecystitis, uncomplicated acute diverticulitis conservative and inpatient or outpatient management with antibiotics should be attempted first wherever applicable. Also, in cases where appendicitis is secondary to a fecolith, a judicious use of Computed Tomography (CT) scan has been advocated and in presence of any unfavourable features, we should consider semi-urgent or emergency surgery. However, many surgeons have argued against these guidelines, as with conservative approach patients may take longer to recover, requiring longer hospital stay and further increasing the risk of hospital acquired infections including COVID infection, which in turn would increase the morbidity of the patients and would incur additional burden on hospitals 9 .

\section{Changes to emergency surgery:}

Patients who require an emergency surgery in COVID era, triple assessment has been recommended with use of proper history, COVID-19 test and recent CT chest (last 24h) or failing that, a Chest X-ray 9. COVID-19 test is a real time reverse transcription polymerase chain reaction (RT-PCR) test which qualitatively detects nucleic acid from SARS-CoV-2 in upper and lower respiratory tract specimen like nasopharyngeal/oropharyngeal swab or bronchoalveolar lavage, collected from patients who are suspected of COVID-19 infection 10. The sensitivity of COVID-19 test has been reported to be $71-98 \% 11$. For patients who needed CT abdomen and pelvis for evaluation of acute abdomen, CT chest is mandatory. These recommendations are based considering the high false negative rate of $2-29 \%$ of COVID-19 testing. It has also been recommended to factor in, the increased risk of adverse outcomes following surgery pertaining to higher risk of acquiring and developing post-operative complication due to COVID-19 infection as inpatient, into planning and consent 12 . Consideration is to be given to stoma formation rather than primary anastomosis in order to reduce the probability of unplanned postoperative critical care for complications.

\section{Staff Protection:}

The guidelines also recommend the use of Personal Protective Equipment (PPE) by all theatre personnel during all operations under general anaesthesia, and infection control practices to be followed based on national and local protocols which advises on level of PPE to be used based on risk from proximity to potential viral load. Droplet transmission increases with aerosol generating procedures (AGP) like endotracheal intubation, bag and mask ventilation, tracheostomy, gastrointestinal endoscopy, naso-gastric tube insertion and while reducing pneumoperitoneum in laparoscopic surgeries and suction of body fluids. AGPs are high risk, hence full PPE is needed while performing them. PPE recommended when dealing with positive or suspected patients includes double layer of disposable gloves and gowns, eye protection/visor and Filtering Face Piece 3 (FFP) mask. It is imperative to practise sterile donning and doffing of PPE in advance. Negative pressure operating rooms (ORs) wherever available should be used for performing the procedures in COVID suspected or confirmed patients. All staffs should have their specific role allocated prior to the procedure to minimise the theatre traffic. It is recommended that high risk patients be intubated and extubated in theatre, and staff immediately present should be at a minimum. Surgeons and scrub staff should wait outside the OR until 10 minutes after induction and intubation 5,6,9,13.

Even though there is no current evidence on virus transmission during abdominal surgeries, early information from Italy, China and previous Severe Acute Respiratory Syndrome (SARS) experience suggest that care should be taken during open procedures also as the smoke plume from coagulating instruments may portray some risk hence adequate arrangement should be made for smoke evacuation from diathermy/other energy devices. The choice of approach (open vs laparoscopy) has been a subject of debate among surgeons. The consensus among surgeons is to prefer open procedure. In a statement published recently, the Association of Laparoscopic Surgeons of Great Britain and Ireland (ALSGBI) found that there is no evidence to suggest increased risk of COVID-19 in laparoscopy as compared to open procedure especially in elective settings. Although literature suggests a theoretical risk of COVID-19 transmission during laparoscopy through the chimney effect, it can be considered in selected individuals where the benefit outweighs the risk of viral transmission $5,6,9,14,15$. If Laparoscopy is used, it is imperative to check the proper functioning of suction system, use of trocars with balloon and suitable size holes to prevent any air leak. It is recommended that the procedure be performed by senior well trained surgeon in order to minimise the operative time and risk of aerosolization, to maintain lowest abdominal insufflation pressure for safe progress (12 $\mathrm{mm} \mathrm{Hg}$ or less ), use of vacuum suction device to extract the surgical smoke during procedure and 
pneumoperitoneum at the end of procedure before removing the specimen and trocars 14,15.

COVID-19 may itself present as an early postoperative complication and adequate measures should be taken to prevent its occurrence. An international, multicentric, observational cohort study done by the COVIDSurg Collaborative, recently published in Lancet, demonstrated that the outcomes of patients with SARSCoV-2 were considerably worse than in pre-pandemic era. The study showed an overall 30-day mortality of $24 \%$ and a morbidity of $51 \%$, mainly from post-operative pulmonary complications which included pneumonia, Acute respiratory distress syndrome (ARDS) and unexpected post-op ventilation 12 .

\section{Staff management and leadership:}

An important limiting factor during the management of patients during COVID-19 era is shortage of the staff 9. The major factor for staff shortage is significant exposure to COVID patients and staffs contracting COVID-19 infection which necessitates some health care staff to self-isolate themselves. Public Health England (PHE) released guidelines on staff testing and return to work for health and social care staff according to which testing should be organised for staff suspected of COVID-19 and should be done within 72 hours of symptom onset as the sensitivity of COVID-19 test reduces thereafter. Staff who tested positive should remain in isolation for 7 days and should only return to work if the symptoms have improved and there is no fever for 48 hours 16 . The situation has been constantly changing and demands every surgeon to take up leadership roles in the hospitals. To facilitate this, surgical review committees have been formed which comprises of surgeons, anaesthetists and nursing staffs who work in an integrated manner and have review meetings at regular intervals to address the changes that need to be implemented for safety of both patients and health care personnel. Surgeons should also take initiative to develop preparedness for potential redeployment into areas of the frontline in ICUs or medical wards that are outside of their regular practice patterns.

\section{Education and Training:}

COVID-19 pandemic also had a great impact on medical/surgical education and training. Trainees and trainers have therefore needed to device an alternate2. method of meeting their needs of adequate training. Because of the need for cross-specialty cover and redeployment, there is an additional demand for COVID19 specific training. Various training and simulation3. courses have been organised in the hospitals to educate and train surgeons in basic management of ICU and critically ill patients. Social distancing, an important element of curbing the spread of corona virus, necessitates development of innovative ways to deliver teaching required for training. One such innovation has been the evolution of seminars into webinars which has become an indispensable tool for imparting education in COVID-19 era. Webinars provides the advantage of interaction between trainee and trainers and hence, facilitates deep and meaningful learning 17. Online teaching materials, virtual/e-learning, videoconferencing, webinars are being organized RCS and various educational institutes worldwide and will play an important part towards trainee education and progression even after COVID-19 era. These modalities can also serve to extend health care services to remote areas which do not have access to adequate healthcare facility especially in lowand middle-income countries.

\section{Conclusion:}

These are uncertain times and the numbers of affected patients seem to be rising daily. A second wave of corona is being foreseen by scientists across the world, hence, it is crucial to consider few aspects before resumption of services. First and foremost, we should be able to see a sustained decline in the number of new COVID-19 patients for a period. We also need to ensure the adequate availability of necessary staff and associated facilities like Intensive care units (ITU), availability of diagnostic testing and clear policies for frequency of testing of staffs and patients, adequate PPE and surgical supplies for the type of procedures performed. Essential perioperative services like diagnostic imaging, anaesthesia, critical care, sterile processing should be adequately accounted for before resumption of elective services. Innovation flourishes during times of crisis. The education of surgical trainees is of paramount importance and should be maintained, even during the difficult times we currently face. While operative skills will be difficult to develop, the use of technology can allow for the remote delivery of expert teaching to a large number of trainees worldwide.

\section{REFRENCES:}

1. Coronavirus Disease (COVID-19) - events as they happen [Internet]. Who.int. 2020 [cited 29 May 2020]. Available from: https://www.who.int/emergencies/diseases/novelcoronavirus-2019/events-as-they-happen

COVID-19 situation reports [Internet]. Who.int. 2020 [cited 29 May 2020]. Available from: https://www.who.int/emergencies/diseases/novelcoronavirus-2019/situation-reports

Wong J, Goh Q, Tan Z, Lie S, Tay Y, Ng S et al. Preparing for a COVID-19 pandemic: a review of operating room outbreak response measures in a large tertiary hospital in 
Singapore. Canadian Journal of Anesthesia/Journal canadien d'anesthésie. 2020;67(6):732-745.

4. [Internet]. Ecdc.europa.eu. 2020 [cited 8 June 2020].16. Available from: https://www.ecdc.europa.eu/sites/default/files/docume nts/covid-19-supply-substances-human-origin.pdf

5. Intercollegiate General Surgery Guidance on COVID-19 UPDATE I The Royal College of Surgeons of Edinburgh [Internet]. The Royal College of Surgeons of Edinburgh. 2020 [cited 3 June 2020]. Available from:17. https://www.rcsed.ac.uk/news-public-

affairs/news/2020/march/intercollegiate-general-

surgery-guidance-on-covid-19-update

6. Updated General Surgery Guidance on COVID-19, 2nd Revision, 7th April 2020 | The Royal College of Surgeons of Edinburgh [Internet]. The Royal College of Surgeons of Edinburgh. 2020 [cited 3 June 2020]. Available from: https://www.rcsed.ac.uk/news-public-

affairs/news/2020/april/updated-general-surgeryguidance-on-covid-19-2nd-revision-7th-april-2020

7. Gorter RR, Eker HH, Gorter-Stam MAW, et al. Diagnosis and management of acute appendicitis. EAES consensus development conference 2015. Surgical Endoscopy.2020; 30: 4668-4690. Available from: https://doi.org/10.1007/s00464-016-5245-7.

8. Ansaloni L, Pisano M, Coccolini F, et al. 2016 WSES guidelines on acute calculous cholecystitis. World J Emerg Surg. 2016;11:25. Available from: https://doi.org/10.1186/s13017-016-0082-5.

9. Cheeyandira A. The effects of COVID-19 pandemic on the provision of urgent surgery: a perspective from the USA. Journal of Surgical Case Reports. 2020; 4:1-2.

10. [Internet]. Files.labcorp.com. 2020 [cited 8 June 2020]. Available from: https://files.labcorp.com/labcorpd8/2020-04/LabCorp-COVID-EUAsum3.pdf

11. Watson J, Whiting PF, Brush JE. Interpreting a COVID-19 test result. BMJ.2020;369: m1808.doi: 10.1136/bmj.m1808

12. Nepogodiev D, Glasbey JC, Li E, Omar OM, Simoes JF, Abbott TE, et al. Mortality and pulmonary complications in patients undergoing surgery with perioperative SARS-CoV2 infection: an international cohort study. The Lancet. 2020. Available from: https://doi.org/10.1016/S01406736(20)31182-X

13. [Internet]. Scts.org. 2020 [cited 3 June 2020]. Available from:

https://scts.org/wpcontent/uploads/2020/03/SCTS-ACTACC-SCPS-TheatreCOVID-pathway-Final.pdf

14. Schwarz L, Tuech JJ. Is the use of laparoscopy in a COVID19 epidemic free of risk? British Journal of Surgery. 2020;107(7).

15. Laparoscopy in The Covid-19 Environment - ALSGBI Position ... [Internet]. [cited 2020Jun8]. Available from: https://www.alsgbi.org/2020/04/22/laparoscopy-in-thecovid-19-environment-alsgbi-position-statement/

. Public Health. COVID-19: management of staff and exposed patients and residents in health and social care settings [Internet]. GOV.UK. GOV.UK; 2020 [cited 2020Jun8]. Available from: https://www.gov.uk/government/publications/covid-19management-of-exposed-healthcare-workers-andpatients-in-hospital-settings.

Ali SR, Dobbs TD, Whitaker IS. Webinars in plastic and reconstructive surgery training - a review of the current landscape during the COVID-19 pandemic. Journal of Plastic, Reconstructive \& Aesthetic Surgery. 2020. Available

from:

https://doi.org/10.1016/j.bjps.2020.05.038

\section{Author contribution:}

Dr Anil Kumar, Dr Meghana Taggarsi, Dr CR Selvasekar have contributed substantially in the conception of the study, design and literature search.

\section{Conflict of Interest: \\ None}

\section{Consent:}

Not required

\section{Funding sources:}

None 